\title{
Lesson of the month 2: An unusual presentation of hyperinsulinaemic hypoglycaemia with possible underlying diagnosis of glucose-sensitive insulinoma or islet cell hyperplasia
}

\author{
Author: Deirdre Maguire ${ }^{\mathrm{A}}$
}

\begin{abstract}
Postprandial hypoglycaemia can occur in islet cell hyperplasia and in reactive hypoglycaemia. Less commonly, it can occur with insulinoma. A case is described where the differential diagnosis was glucose-sensitive insulinoma or islet cell hyperplasia. Typical provocation was prolonged exertion or fasting followed by ingestion of sugary snacks resulting in hypoglycaemic seizures and collapse. Biochemistry and computerised tomography imaging were consistent with an insulinoma in the pancreatic tail, but this was not confirmed on endoscopic ultrasound. Selective intra-arterial calcium stimulation with hepatic venous sampling results suggested a diagnosis of islet cell hyperplasia. Ten years later, repeat imaging was consistent with a neuroendocrine tumour. Surgical resection has resulted in remission of symptoms. The patient will be monitored long term to ensure no recurrence.
\end{abstract}

KEYWORDS: Glucose-sensitive insulinoma, islet-cell hyperplasia, selective intra-arterial calcium stimulation, neuroendocrine tumour

\section{Case report}

A 34-year-old farmer presented to the accident and emergency department in 2002 with a generalised tonic-clonic seizure secondary to hypoglycaemia. Inpatient- 72 hour fast was terminated due to a blood glucose of $2.4 \mathrm{mmol} / \mathrm{L}$. Plasma insulin level was inappropriately high at $8.4 \mathrm{mU} / \mathrm{L}$ (normal range, 1.6-10.9), with an insulin C-peptide level of $0.94 \mathrm{nmol} / \mathrm{L}$ (normal range, 0.11-0.61). Computerised tomography (CT) scan revealed a $15 \times 17-\mathrm{mm}$ lesion in the pancreatic tail adjacent to splenic hilum. He was commenced on diazoxide and referred to a tertiary centre. Endoscopic ultrasound was arranged to determine whether the lesion could be resected laparoscopically; however a lesion in the tail of pancreas was not located.

Selective intra-arterial calcium stimulation (SACS) with hepatic venous sampling showed a generalised hyper-response with most stimulated insulin levels more than twice the baseline levels (Table 1). The biggest increases were seen in

Author: ${ }^{\text {A }}$ consultant in diabetes and endocrinology, Diabetes and Endocrinology, Harrogate District Hospital, Harrogate, UK the superior mesenteric and inferior pancreatico-duodenal arteries. It was felt that the patient most likely had generalised islet cell hyperplasia. He was treated medically with diazoxide $100 \mathrm{mg}$ tds. Unfortunately, he did not attend subsequent followup appointments.

The patient's GP referred him back in 2013. He was no longer taking diazoxide as he was concerned it could provoke fluid retention. He developed symptoms with prolonged fasting or exertion followed by ingestion of sugary foods. He was taught how to monitor his capillary blood glucose and was given appropriate dietary advice. His HbAlC was $30 \mathrm{mmol} / \mathrm{mol}$. A repeat CT scan revealed a $15 \times 19-\mathrm{mm}$ hyper-enhancing lesion at the tip of the pancreas with a clear feeding vessel, suggestive of neuroendocrine tumour.

His care was discussed at the pancreatic multidisciplinary team (MDT). Sulphur colloid scan excluded the differential diagnosis of intra-pancreatic spleen. Chromogranin A level was normal. Distal pancreatectomy was performed July 2014. Histology showed a well differentiated neuroendocrine tumour (grade I; pT2, pNx, pMx). The tumour stained positive for insulin, but negative for glucagon, gastrin and somatostatin. There was a small amount of pancreatic tissue showing some background islet cell micro-adenomatosis and minimal focal chronic inflammation. Subsequent neuroendocrine MDT discussion recommended annual follow-up with chromogranin $A$ and further cross sectional imaging only if marker levels rising or symptoms suggestive of recurrance.

Post operatively the patient feels better than has done in his whole life. He can now eat ice cream without consequence. Four months post operatively he had an oral glucose tolerance test performed with baseline plasma glucose $4.5 \mathrm{mmol} / \mathrm{L}$ and twohour plasma glucose of $4.7 \mathrm{mmol} / \mathrm{L}$. At review at nine months, he remains in remission with a $\mathrm{HbAlC}$ of $36 \mathrm{mmol} / \mathrm{mol}$.

\section{Discussion}

Insulinoma should be suspected in the presence of Whipple's triad. This consists of symptoms or signs of hypoglycaemia, confirmed hypoglycaemia, and relief of symptoms or signs with administration of glucose.

The gold standard test for diagnosis is the 72-hour fast. Endocrine society clinical practice guidelines from 2009 conclude that endogenous hyperinsulinaemia exists with 
Table 1. Selective intra-arterial calcium stimulation with hepatic venous sampling: summary of results.

\begin{tabular}{lll} 
Arterial site & $\begin{array}{l}\text { Baseline } \\
\text { insulin level } \\
\text { pmol/L }\end{array}$ & $\begin{array}{l}\text { Peak insulin level } \\
\text { after calcium } \\
\text { infusion pmol/L }\end{array}$ \\
$\begin{array}{l}\text { Superior mesenteric: } \\
\text { middle and left }\end{array}$ & 153 & 1,500 \\
$\begin{array}{l}\text { Superior mesenteric: right } \\
\text { Inferior pancreatico- }\end{array}$ & 124 & 1,830 \\
$\begin{array}{l}\text { duodenal: left } \\
\text { Inferior pancreatico- }\end{array}$ & 236 & 2,270 \\
duodenal: right & 199 & 4,100 \\
Right distal splenic & 110 & 468 \\
Left atrium & 393 & 156 \\
Proximal splenic: left & 409 & 1,290 \\
Proximal splenic: right & 316 & 710 \\
Gastro-duodenal: left & 438 & 1,540 \\
Gastro-duodenal: right & 438 & 600 \\
\hline ahighest level, whether 30 or 60 seconds recorded. &
\end{tabular}

serum glucose $<3.0 \mathrm{mmol} / \mathrm{L}$ and plasma insulin level of at least $3 \mu \mathrm{U} / \mathrm{mL}$ (18 pmol/L), C-peptide of at least $0.6 \mathrm{ng} / \mathrm{ml}$, proinsulin levels of at least $5 \mathrm{pmol} / \mathrm{L}$ and $\beta$-hydroxybutyrate levels of $2.7 \mathrm{mmol} / \mathrm{L}$ or less. Sulphonylurea screen should be negative. ${ }^{1}$ Insulin antibodies should be checked to exclude insulin autoimmune syndrome. ${ }^{1}$

Post-prandial hypoglycaemia occurs more commonly in islet cell hyperplasia. However, in one series, $6 \%$ of insulinomas had isolated postprandial hypoglycaemia. ${ }^{2}$ The case described was diagnosed with a standard 72-hour fast. There are case reports of patients with glucose-sensitive insulinomas who have not become hypoglycaemic on a prolonged fast, but have been found to have an exaggerated insulin response during a glucose tolerance test, accompanied by significant hypoglycaemia and neuroglycopenic symptoms. ${ }^{3}$ lnitial low HbA1C may help differentiate between insulinoma and early glucose intolerance with reactive hypoglycaemia. ${ }^{4}$ However, there are case reports of insulinomas developing in patients with type-2 diabetes. ${ }^{5,6}$

Radiologically, the pancreatic tail lesion could have been an insulinoma. $90 \%$ of insulinomas are less than $2 \mathrm{~cm}$ in diameter. ${ }^{7}$ Endoscopic ultrasound scan (EUS) has a blind spot at the splenic hilum which could explain why it was missed on this imaging. Biphasic thin-section helical CT scan and EUS combined has a sensitivity of almost $100 \%$ in localising insulinomas. ${ }^{8}$ If non-invasive radiological tests fail to locate the lesion with certainty, then both EUS and SACS should be performed. ${ }^{9}$

The SACS result of the current patient was not suggestive of a pancreatic tail lesion. A two-fold step-up in right hepatic vein insulin concentration from baseline at times 20, 40 and/or 60 seconds after arterial calcium injection indicates a positive response. A positive response when the gastro-duodenal artery or superior mesenteric artery is injected suggests a head or neck lesion. A positive response when the proximal or mid splenic artery is injected suggests a body or tail lesion.
False-negative SACS can occur in glucose-sensitive insulinomas or with diazoxide treatment, but this seems unlikely to be the case here as there is generally an increase in insulin levels after calcium stimulation.

In one study of 45 surgically proven insulinomas with positive biochemical tests but negative localisation studies, SACS had an $84 \%$ sensitivity and was felt to be a useful tool in preoperative localisation; ${ }^{10} 11 \%$ had false-negative tests and $4 \%$ had falsepositive localisation. There was a positive response in $>1$ artery in $53 \%$ of cases and the dominant site was used to predict location of the tumour. Sensitivities were similar for head/neck and body/tail lesions. Anatomical variants and technical errors of catheterisation are likely causes of false-localisation and false-negative results.

Distal pancreatectomy is not generally recommended for islet cell hyperplasia due to the potential risk of ongoing or subsequent recurrent hypoglycaemia related to residual hyperplastic islet cells. Imaging was consistent with a focal neuroendocrine tumour and this was confirmed histologically. Post-operatively he is in remission. The significance of the small amount of background islet cell microadenomatosis is unclear. This can be associated with von Hippel-Lindau disease and multiple endocrine neoplasia type I syndrome. ${ }^{11} \mathrm{He}$ has no clinical features to suggest either syndrome. Chromogranin A levels can be helpful in diagnosis, as well as follow up of pancreatic neuroendocrine tumours. ${ }^{11}$ The patient will be monitored long term in outpatients to ensure no recurrence.

\section{References}

1 Cryer PE, Axelrod L, Grossman AB et al. Evaluation and management of adult hypoglycaemic disorders: an Endocrine Society clinical practice guideline. J Clin Endocrine Metab 2009;94:709-28.

2 Placzkowski KA, Vella A, Thompson GB et al. Secular trends in the presentation and management of functioning insulinoma at the Mayo Clinic, 1987-2007. J Clin Endocrinol Metab 2009;94:1069-73.

3 Izumiyama $\mathrm{H}$, Gotyo $\mathrm{N}$, Fukai $\mathrm{N}$ et al. Glucose-responsive and octreotide-sensitive insulinoma. Intern Med 2006;45:519-24.

4 Han JF, Zhang F, Bao YQ et al. Diagnostic value of parameters of glucose metabolism as screening tests for insulinoma. Zhonghua $Y i$ Xue Za Zhi 2010;90:1093-6, abstract in English; article in Chinese.

5 Madathil A, Weaver J. Insulinoma presenting as postprandial hypoglycaemia. BMJ Case Rep 2011;pii:bcr0720114477.

6 Munir A, Toh SL, Arutchelvam V. Insulinoma in a patient with type 2 diabetes. Practical Diabetes 2011;28:226-a.

7 Chatziioannou A, Kehagias D, Mourikis D et al. Imaging and localisation of pancreatic insulinomas. Clin Imaging 2001;25:275-83.

8 Vaidakis D, Karoubalis J, Pappa T et al. Pancreatic insulinoma: current issues and trends. Hepatobiliary Pancreat Dis Int 2010;9:234-41.

9 Tamagno G, O'Shea D. Anatomical localisation of insulinomas: still a need to combine a set of diagnostic procedures. Hormones 2012;11:483-7.

10 Guettier J, Kam A, Chang R et al. Localisation of insulinomas to regions of the pancreas by intra-arterial calcium stimulation: the NIH experience. J Clin Endocrinol Metab 2009;94:1074-80.

11 Cassol C Mete O. Endocrine manifestations of von Hippel-Lindau disease. Arch Pathol Lab Med 2015;139:263-8.

Address for correspondence: Dr D Maguire, Harrogate District Hospital, Lancaster Park Road, Harrogate, North Yorkshire HG2 7SX, UK.

Email: deirdremaguir3@hotmail.com 